\title{
DERECHO JUDICIAL
}





\section{Michele Taruffo}

Universidad de Pavia, Italia

taruffo@unipv.it

\section{Sobre la complejidad de la decisión judicial ${ }^{*}$}

The Complexity of Judicial Decision

Sobre a complexidade da decisão judicial

Artículo de investigación: recibido 02/02/2012 y aprobado 23/10/2012

Traducción del italiano a cargo de Carlos Mondragón, profesor Hora Cátedra de la Universidad Icesi. 



\title{
Resumen
}

Con el presente artículo se pretende explicar la complejidad y la función fundamental de la decisión judicial y se sostiene que el fin de la decisión judicial consiste en resolver una controversia según criterios legales y racionales controlables. Para lograr el objetivo propuesto, el autor se refiera a las dimensiones (i) Dialéctica, (ii) Epistemológica, (iii) Jurídica, (iv), Lógica, (v) Axiológica, (vi) y del sentido común, como categorías explicativas del razonamiento judicial. Se concluye que el proceso de construcción del razonamiento argumentativo del juez, al momento de motivar su decisión, es complejo porque no depende de un solo sistema o dimensión, sino que, por el contrario se nutre de diversas disciplinas, estructuras lógicas, cognoscitivas e incluso de la experiencia como premisa justificativa.

Palabras Clave: Decisión Judicial, Motivación de la decisión judicial, Razonamiento judicial, Valoración judicial de los hechos, Verdad procesal.

\begin{abstract}
This article aims to explain the complexity and the crucial role of judicial decision and argues that the purpose of the judicial decision consists of settling a controversy according to legal and controllable rational criteria. To achieve the proposed goal, the author refers to the (i) Dialectical, (ii) Epistemological, (iii) Juridical, (iv) Logical, (v) Axiological, and (vi) common sense dimensions, as explanatory categories of judicial reasoning. It is concluded that the construction process of the argumentative reasoning of the judge, at the time of motivating its decision, is complex because it does not depend on a single system or dimension, but on the contrary, it is based on diverse disciplines, on logical and cognitive structures, and even on experience as a justifying premise.

Keywords: Judicial decision, Motivation of the judicial decision, Judicial reasoning, Judicial assessment of the facts, Procedural truth.
\end{abstract}

\section{Resumo}

Neste artigo, pretende-se explicar a complexidade e a função fundamental da decisão judicial, sustentando que a finalidade da decisão judicial consiste em resolver uma controvérsia de acordo com critérios legais e racionais controláveis. Para atingir este objetivo, o autor refere-se às dimensões (i) Dialética, (ii) Epistemológica, (iii) Jurídica, (iv), Lógica, (v) Axiológica, (vi) e do senso comum, como categorias explicativas do razoamento judicial. Conclui-se que o processo de construção do razoamento argumentativo do juiz, no momento de motivar sua decisão, é complexo porque não depende de apenas um sistema ou dimensão, mas que, pelo contrário, é nutrido de diversas disciplinas, estruturas lógicas e cognoscitivas e até da experiência como premissa justificativa.

Palavras-chave: Decisão judicial, motivação da decisão judicial, razoamento judicial, valorização judicial dos fatos, verdade processual. 



\section{Introducción}

Recientes investigaciones desde la perspectiva argumentativa han considerado de manera particular los argumentos que se vienen desarrollando dentro del proceso judicial, y han analizado también, los argumentos que el juez tiene en cuenta para motivar la decisión final de la controversia ${ }^{1}$. Estos estudios han permitido dejar en evidencia aspectos de la decisión judicial que, de otra manera, hubieran pasado inobservados, y que sin embargo, implican el riesgo de sugerir una imagen excesivamente simplificada y monodimensional de un fenómeno que por el contrario presenta numerosos aspectos problemáticos y aparece constituido por la combinación compleja de varias dimensiones. Quedando en firme, entonces, que la decisión judicial se traduce en un argumento desarrollado por el juez que puede ser analizado de manera útil, con los instrumentos ofrecidos por el estudio de la construcción de dichos argumentos, siendo oportuno hacer alusión, al menos de manera sintética, a algunos de los principales perfiles de complejidad de tales decisiones.

Para realizarlo en pocas páginas es necesario moverse, casi paradójicamente, desde una concepción simplificada de la decisión judicial, excluyendo de la discusión variantes y variables ulteriores, cuyo análisis requeriría un desarrollo imposible en este contexto. Así, a manera de ejemplo, no se pueden tomar en consideración los problemas que caracterizan una formulación colegiada de la decisión, frente a un caso, en el cual, decidir corresponde a un solo juez, así como tampoco, se pueden tomar en consideración las peculiaridades de las situaciones en las cuales, como sucede por ejemplo en el jury trial norteamericano, la valoración de las pruebas y la decisión sobre los hechos está a cargo de un grupo de ciudadanos escogidos a la suerte y desprovistos de preparación jurídica, mientras la decisión en derecho es formulada por un juez profesional del derecho. Es conveniente entonces, examinar la hipótesis más simple, que es, de hecho, la más frecuente en nuestro ordenamiento y en muchos otros, en los cuales la decisión es formulada en todos sus aspectos por un solo juez dotado de preparación técnco-jurídica.

En cada caso resulta necesario tener presente que la función fundamental de la decisión judicial consiste en resolver una controversia según criterios legales y racionales controlables, y que tal función se realiza en el momento en que

\footnotetext{
${ }^{1}$ En literatura italiana ver Di Donato (2008: 183), Taruffo, (2009: 183) y la referencia obligatoria a Amsterdam \& Bruner (2000), y de manera más general Bruner (2002).
} 
el juez toma una decisión final en el procedimiento individual, entre diversas soluciones hipotéticamente posibles del conflicto (Taruffo, 2009: 193). Se considera además como regla que el juez es llamado a motivar, es decir a justificar su decisión, dado que en este sentido operan principios constitucionales y normas procesales ordinarias, y que precisamente en el configurar este "discurso justificativo", el juez construye su argumentación relativa a los aspectos facticos de la decisión que ha tomado. ${ }^{2}$

\section{La dimensión dialéctica.}

Una dimensión importante de la decisión judicial puede definirse dialéctica por las razones que se explican enseguida. Esta dimensión es en realidad doble: se puede, de hecho, hablar de una dimensión dialéctica diacrónica, que se articula en el tiempo y lugar en qué se desarrolla el proceso, y una dimensión dialéctica sincrónica, que se refiere a la estructura de la argumentación que el juez expone en la decisión final.

La dimensión dialéctica diacrónica queda en evidencia si solo se considera que la decisión judicial no proviene de uno actu al final del proceso, sino que es el resultado final de un procedimiento largo a través del cual se formulan y adquieren las premisas que determinarán la decisión ${ }^{3}$. Sí también se considera el proceso como una secuencia de argumentos provenientes de varios temas con diversas finalidades (Taruffo, 2009: 43), no se puede desconocer que la presentación de estos argumentos sigue un esquema dialéctico que determina la estructura misma del procedimiento. Cuando se subraya que el "Contraddittorio" no solo representa una garantía fundamental de las partes, sino que constituye el método esencial que se sigue dentro del proceso para llegar a una formulación correcta de la decisión ${ }^{4}$, se centra la atención en el hecho que tal método se funda en la dialéctica de las partes, y que esta dialéctica se articula en afirmaciones y respuestas, movidas y contramovidas, réplicas y contrarréplicas, según determinaciones en buena manera ordenadas en la medida que son disciplinadas específicamente por la ley procesal. ${ }^{5}$ Entonces los argumentos que las partes desarrollan dentro del proceso siguen este orden dialéctico y es, en este orden, que el juez llega a su conocimiento

\footnotetext{
2 Sobre los fundamentos de la sentencia como un discurso de justificación, ver Taruffo (1975: 107), (2009: 237).

3 En ciertos aspectos de esta dinámica que tiene lugar durante el proceso, ver Taruffo (2002).

4 Para este propósito ver L'integrazione dell'art.101 c.p.c., il contraddittorio sulle questioni rilevate d'ufficio e la "scommessa aperta" dell'ordinamento processuale (Taruffo, 2010: 65).

5 Véase, por ejemplo, el artículo 183 del Código Procesal Civil italiano.
} 
y los toma en consideración. De otraparte, se considera que el juez participa de la dialéctica procesal, que entonces involucra típicamente tres sujetos y no dos, todas las veces que pronuncia una sentencia parcial o resuelve cuestiones relativas al procedimiento (por ejemplo admitiendo o excluyendo las pruebas aportadas por las partes o disponiendo pruebas de oficio). También puede suceder que el mismo juez determine el contenido y la forma de argumentos propuestos por otros sujetos, cuando por ejemplo, como sucede en nuestro procedimiento civil, es el juez quien interroga al testigo (bien sea sobre los hechos "rendidos" por una de las partes), y es el mismo juez el autor del recuento que contiene la narración de los hechos desarrollados por el testigo ${ }^{6}$. Se trata entonces de una dinámica dialéctica que puede ser bastante compleja, que inicia con el acto introductorio del proceso y prosigue a lo largo de todo el procedimiento hasta desembocar en la decisión que lo concluye.

Como se mencionó previamente, la dimensión dialéctica sincrónica considera la estructura argumentativa del discurso que el juez desarrolla en la sentencia. La función esencial de la motivación es justificar la decisión que el juez ha formulado, pero también, dentro del ámbito de este discurso justificativo, es fácil identificar una estructura dialéctica. Por un lado, aunque en la decisión del juez se refleje la contraposición entre los argumentos desarrollados por las partes en el sentido de sostener las respectivas razones, dado que estas argumentaciones representan en realidad el objeto sobre el cual recae la decisión final. No se afirma que el juez deba escoger necesariamente entre los argumentos desarrollados por las partes (pudiendo él formular una hipótesis propia de solución a la controversia cuando ninguna de las hipótesis formuladas por las partes le parezca apropiada), pero eso no inhibe que él deba tomar en consideración los elementos de juicio que provengan de la "competición" dialéctica que se desarrolla entre las partes en el curso del proceso. En particular, se puede decir que el juez no pudiendo excluir el conocimiento de los hechos de la propia "ciencia privada", tiene la obligación de tomar en consideración las pruebas que las partes han aportado, y emitir, con justificación, las valoraciones propias frente al caso (Carratta \& Taruffo, 2011: 477-482). Entonces, la “motivación de hecho" se funda en la decisión final que el juez formula a la conclusión dialéctica probatoria que las partes han desarrollado durante el curso del proceso. Lo anterior implica que el juez debe argumentar críticamente sobre varios aspectos de esta

\footnotetext{
${ }^{6}$ Una aproximación crítica a este sistema: Dittrich (2011: 114).
} 
dialéctica y sobre los contenidos que de la misma surjan, dado que no puede dejar de respetar el derecho a la prueba que le asiste a ambas partes, y se manifiesta puntualmente en la posibilidad de deducir, hacer asumir y valorar todas las pruebas directas y contrarias relativas a cada hecho relevante de la controversia (Taruffo, 2010: 482).

\section{La dimensión epistemológica}

En los sistemas que, como el nuestro, se inspiran en el principio de legalidad, la solución de las controversias debería ocurrir a través de la correcta aplicación de la norma jurídica que regula el caso. Lo anterior le introduce a la decisión judicial la necesaria dimensión jurídica, aunque como se verá, es necesario considerar que la correcta aplicación de la norma que regula el caso, presupone que hayan sido verificados los hechos a los cuales, determinada norma asigna ciertas consecuencias jurídicas. Sí se considera la estructura condicional de la norma "F, entonces CG" (Es decir: Sí se ha verificado el hecho del tipo F, entonces se tiene la consecuencia jurídica CG), se entiende con facilidad que la decisión por la cual "se ha verificado un hecho del tipo F" es una condición necesaria para la aplicación de la norma y para la existencia de las consecuencias jurídicas que la misma provee. En esta perspectiva, se puede decir que la verificación de la verdad de los hechos relevantes de la controversia es una condición necesaria (aunque no la única), de la justicia de la decisión.?

En el momento que se reconoce que una de las finalidades que persigue el proceso es la verificación sobre la veracidad de los hechos, y que entonces el juez deberá decidir sobre la verdad o falsedad de los enunciados que le describen, se reconoce la existencia de una dimensión epistemológica del proceso y de la decisión que lo concluye. Sobre todo, el proceso entero puede ser interpretado como una actividad compleja en la cual participan varios sujetos, que tiene carácter epistemológico en cuanto se propone establecer la verdad de los hechos relevantes (Taruffo, 2009: 135). Basta observar que toda la fase del proceso que consiste en la adquisición de los medios de prueba, no tiene otro sentido que el de recopilar y proveer la información que sea necesaria, precisamente, para decidir sobre la veracidad o falsedad de los enunciados que narran estos hechos. En otros términos, el proceso tiene una función en sentido lato, cognoscitiva,

\footnotetext{
7 A este respecto, ver Taruffo (2009: 113). La discusión no puede ser detallada profudamente y plantea un debate considerable en la literatura, por ejemplo Cavallone (2010: 1) y Taruffo (Contro la veriphobia. Osservazioni sparse in risposta a Bruno Cavallone, 2010: 995).
} 
e incluye entre sus aspectos esenciales la recolección de los elementos de conocimiento (pruebas) que sean necesarios para fundamentar la decisión final. Esta decisión, a su vez, tiene una clara dimensión epistemológica en cuanto el juez, en la decisión sobre los hechos de la causa, dice cuáles enunciados de hecho son veraces y cuáles no lo son. O también, cuales no resultan demostrados: su argumentación, entonces, establece la veracidad de los hechos que le son objeto. ${ }^{8}$

Por otra parte, el discurso que el juez desarrolla en la sentencia, y en particular en la motivación de la decisión sobre los hechos, no consiste solo en la enunciación de cuales hechos son veraces y cuáles no lo son: como se ha dicho ya, la motivación es un discurso justificativo en el cual el juez debe aducir las razones por las cuales su decisión resulta fundada. La justificación de la decisión sobre los hechos, que debe ser fundada exclusivamente sobre la referencia a las pruebas que han sido allegadas al proceso, asume necesariamente una estructura de inferencia: cada afirmación relativa a la verdad de un enunciado de hecho, debe ser justificado sobre la base de la inferencia que asume la prueba como premisa y llega a la conclusión constituida por la verdad del enunciado de hecho al cual se refiere la prueba'. Entonces, cuando habla de los hechos de la causa, el juez no se limita a narrar cualquier historia: la historia que narra presenta una clara dimensión epistemológica en cuanto incluye la afirmación de la verdad de los hechos de los cuales habla, o bien la confirmación probatoria de esta afirmación, mediante la referencia a los datos cognoscitivos que justifican tal afirmación. ${ }^{10}$

\section{La dimensión jurídica.}

El vínculo del juez (que está sujeto solamente a ley, como dice el Art. 101 apartado segundo de la Constitución) a decidir en derecho, y su obligación consecuente de aplicar correctamente en la decisión la norma de derecho que regula el caso, determinan la existencia, en tal decisión, de una necesaria y fundamental dimensión jurídica. De hecho, la decisión se fundamenta en este punto de vista sobre la aplicación de la norma, que a su vez presupone la escogencia y la

\footnotetext{
8 Sobre la diferencia entre la narrativa "buena" y la "verdadera", en el contexto del proceso, ver Taruffo (2009: 67).

9 Una aproximación más detallada de la estructura lógica de estas inferencias en (Taruffo, 2009: 207).

10 Se da la bienvenida aquí, sin ser capaz de justificar por razones de espacio, una concepción de la evaluación racional de las pruebas y el razonamiento lógico-con-estructura con la que el tribunal extrae conclusiones en términos de verdad o falsedad de las declaraciones relacionadas con los hechos de la causa (Beltrán, 2007); Taruffo, Art.116 (Carratta y Taruffo, 2011: 519).
} 
interpretación de la norma que se aplica a los hechos de la controversia en particular (Tarello, 1980). ${ }^{11}$ La dimensión jurídica de la decisión es principalmente, una decisión hermenéutica (En el significado amplio del término), en cuanto se centra en la elección e interpretación de la norma que regula el caso (Viola \& Zaccaria, 1999) (Carlizzi \& Omaggio, 2010).

Esta dimensión es muy importante, no solo porque de la correcta interpretación y aplicación de esta norma depende obviamente la justicia de la decisión, sino porque la dimensión hermenéutica es determinante en la formulación de la decisión, en cuanto considera la estructura del discurso que el juez desarrolla en la motivación de la sentencia. Bajo el primer perfil, el juez, como cualquier intérprete, debe sobre todo determinar cuál es el significado de la disposición normativa a la cual se hace referencia, escogiendo entre los varios significados posibles de tal disposición (Carlizzi \& Omaggio, 2010: 96). ${ }^{12}$ Lo anterior implica un conjunto de operaciones que pueden ser también, bastante complicadas, en las cuales encuentra aplicación el vasto repertorio de los instrumentos interpretativos que los filósofos del derecho han estudiado desde hace tiempo y sobre lo cual existe una inmensa bibliografía. ${ }^{13}$ Estas operaciones y estos instrumentos no pueden ser analizados aquí, ni siquiera de forma sumaria, sin embargo, es necesario tener en cuenta el hecho del "descubrimiento" de la solución jurídica correcta, en relación a los hechos del caso y de consecuencia la individualización de la solución jurídica adecuada de la controversia, exige al juez un razonamiento que puede presentar aspectos de gran complejidad. Esto que se subraya de manera particular, es un aspecto de gran importancia que se analiza especialmente desde la teoría hermenéutica, es decir que la interpretación judicial del derecho, centrada en la aplicación de la norma como regla de juicio en el caso concreto, no se manifiesta desde un análisis abstracto de la norma en si considerada, se manifiesta, del hecho específico que determina el fundamento de la controversia, y es en consideración del hecho que el juez escoge la interpretación más adecuada de la norma que considera aplicable al caso en particular (Carlizzi \& Omaggio, 2010: 102).

Bajo el segundo perfil, que considera directamente el discurso que el juez de-

11 Sobre la distinción entre la aplicación y la interpretación de la norma, ver Tarello (1980: 42).

12 Sobre el carácter y los límites de esta elección, que se aplican al juez como a cualquier intérprete de cualquier texto, consulte, generalmente, Eco (1990: 22).

13 Además del texto de Tarello ya mencionado, en la reciente literatura italiana ver, por ejemplo, Guastini (2004) y (1993), Zachary (1990), Luzzati (1999), Luzzati (1990). 
sarrolla en la sentencia, la dimensión jurídica determina aspectos esenciales de la estructura lógica de dicho discurso, y que han sido objeto de estudios muy interesantes (Chiassoni, 2007: 11). Aunque la decisión del juez que considera la elección de la norma y del significado relativo, y que viene aplicada como regla de juicio del caso, debe ser justificada con argumentos racionalmente controlables, lo que implica el uso de formas lógicas idóneas para fundamentar la validez jurídica de la decisión (Chiassoni, 2007: 21, 29, 44). Entre estas formas resulta particularmente importante aquella que se funda sobre una inferencia de tipo deductivo-silogístico que constituye el núcleo lógico de la justificación interna de la decisión (Chiassoni, 2007). Sin profundizar aquí los numerosos aspectos de la justificación jurídica de la decisión judicial, lo que se subraya es que al considerar la argumentación del juez, éste asume una estructura lógico-justificativa particularmente fuerte: no se trata simplemente de "narrar el derecho", sino de justificar la decisión, argumentando de una forma lógicamente estructurada, las razones por las cuales el juez decidió que aquella norma, con aquel significado, es aplicada a aquellos hechos, así como el resultado acertado (Carlizzi \& Omaggio, 2010: 93).

\section{La dimensión lógica}

Las consideraciones desarrolladas en los párrafos precedentes han hecho cada vez más referencia a la racionalidad y a la lógica del discurso que el juez desarrolla en la sentencia exponiendo la motivación de su decisión, o mejor: las motivaciones de sus decisiones, dado que la decisión judicial es en realidad el fruto de un contexto estructurado de decisiones que consideran los varios aspectos de hecho y de derecho de la controversia.

Parece evidente que la actividad decisoria del juez presenta una dimensión lógica particularmente relevante. De una parte, para conseguir formular la decisión el juez debe motivar un "Contexto de descubrimiento" que implica la utilización de instrumentos racionales y de forma lógica, so pena que la decisión no sea otra cosa que el fruto de un acto irracional y arbitrario. En lo que respecta a la individualización de la norma de derecho que regula el caso, se han ya señalado los criterios de la hermenéutica y de la técnica que se utilizan para llegar a la correcta interpretación de las disposiciones normativas. En lo que se refiere a la decisión sobre los hechos, se ha hecho ya referencia a la inferencia que el juez formula para valorar los resultados de las pruebas de las cuales dispone, y para derivar de ellas consecuencias en orden a los enunciados fácticos con los cuales debe establecer la veracidad o falsedad. Aquí se pude agregar que en la fase de descubrimiento de 
la decisión, y también en el trascurso del procedimiento, encuentra espacio un instrumento lógico peculiar bajo el nombre de abduzione (Tuzet, 2006).

Se trata, en síntesis, del argumento a través del cual, se parte de un evento conocido (el indicio), para formular hipótesis frente a una versión posible de cómo podría ser verificado el hecho que se trata de demostrar (por esto se dice que la abduzione es el razonamiento típico de Sherlock Holmes). Naturalmente tal versión no representa más que una hipótesis que podría ser confirmada o refutada por las pruebas (Tuzet, 2006: 258). En el caso en que las pruebas no las confirmaran, sería necesario formular otra hipótesis de someter al control, y así en una secuencia que se desarrolla según la lógica del trial and error, (o del Galiliano probando y reprobando), y se concluye solo cuando se llega a formular una hipótesis que resulta confirmada como verídica desde los conocimientos disponibles (Tuzet, 2006: 278). Pensando a la par de estas operaciones de "descubrimiento" de la decisión, se puede entonces hablar de una compleja actividad guiada por criterios de racionalidad heurística, dotados de específicas formas lógicas.

De otra parte, y en lo que respecta el discurso con el cual el juez justifica la decisión propia en la motivación de la sentencia, es decir, el "contexto de justificación”, se ha hecho ya alusión, bien a la justificación de la decisión en derecho, como a la justificación de la decisión de hecho. A este punto solo se puede agregar que en su conjunto la decisión judicial correcta presenta una estructura lógica fundamental en la cual deben existir la justificación interna, a la cual se ha hecho ya referencia, que se deriva de la correlación lógica (normalmente de forma deductiva), entre la premisa de derecho y la premisa de hecho de la decisión, como también deben estar presentes las justificaciones externas de tales premisas, es decir, los argumentos con los cuales se justifica la premisa de derecho y los argumentos con los cuales se justifican la verificación de los hechos de la causa (Chiassoni, 2007: 14).

Es evidente que el discurso con el cual el juez enuncia su propia decisión en la sentencia, es un discurso justificativo, lógicamente estructurado en todos sus aspectos y a varios niveles.

\section{La dimensión axiológica.}

Un aspecto muy importante del razonamiento a través del cual el juez llega a la decisión, y entonces, también del discurso que él desarrolla cuando enuncia y justifica sus propias decisiones, involucra los juicios de valor que formula en el curso del iter decisorio y que se deben expresar en la decisión final. Se puede entonces hablar con razón, de una dimensión axiológica de la decisión judicial, haciendo, 
a propósito, referencia a las valoraciones formuladas y expresadas por el juez. Es seguramente útil, subrayar que tal dimensión está presente en todos los aspectos de su razonamiento y de la decisión con la cual se concluye el tema.

De una parte, de hecho, sí es verdad que sobre los enunciados relativos a los hechos de la causa el juez debe formular juicios en términos de falso y verdadero, es también verdad que en el razonamiento sobre los hechos el juez debe con frecuencia, formular valoraciones en sentido propio, es decir, juicios fundados sobre criterios axiológicos. A veces esto sucede porque las normas contienen aquello que, Wroblewski ha definido como "determinación valorativa" del hecho (Wroblewski, 1983: 108) (Taruffo, 1992: 105). Es decir, la determinación del hecho al cual la norma debería aplicarse en términos no solamente descriptivos, sino tales que reclaman por parte del juez, la formulación de un juicio de valor. En estos casos la enunciación del hecho que el juez formula tiene una estructura compleja porque incluye un enunciado descriptivo que expresa la valoración (en términos de verdadero/falso) de determinadas circunstancias de hecho, pero también incluye un enunciado valorativo con base en el cual se establece que tales circunstancias corresponden a la determinación valorativa prevista en la norma. Se considera también que esta determinación valorativa es efectuada por el legislador en una pluralidad de modos, y no rara vez, también el criterio de la valoración se conmina a la elección del juez (Taruffo, 1992: 111).

Otras veces esto sucede porque, para llegar a establecer la verdad o falsedad de un enunciado que describe un hecho de la causa, el juez debe formular valoraciones, relativas, por ejemplo, a los elementos que determinan la credibilidad o no credibilidad de un testimonio, o la "normalidad" de un determinado evento o comportamiento.

De otro lado, también la interpretación de las normas dirigida a su aplicación, exige la formulación de juicios de valor, bien porque a menudo, como se ha dicho, también las premisas fácticas de la norma son definidas con términos valorativos, bien porque la determinación de los posibles significados de la norma requiere juicios de valor en cuanto la disposición que se trata de interpretar es formulada en términos valorativos, de modo que, su significado como regla de juicio del caso concreto puede ser establecido solamente a través de valoraciones. Entonces, la elección del significado que se adopta, implica cada vez, elecciones de valor, así como requiere elecciones de valor la determinación de las consecuencias jurídicas que la aplicación de la norma produce frente al caso en particular. Lo anterior vale para cualquier género de norma, pero es claro que momentos de opción axiológica 
son inevitables, y son particularmente importantes, cuando la disposición se refiere a disposiciones que expresan principios generales (como las normas Constitucionales), o normas "vagas" que contienen clausulas generales, cuya "eterointegrazione" (Heterointegración) requiere necesariamente valoraciones (Luzzati, 1990: 279-299).

Sin profundizar ulteriormente, en el análisis de las numerosas circunstancias, en las cuales el juez debe formular juicios de valor, se puede observar que la dimensión axiológica está presente en muchos momentos de la decisión sobre los hechos y de la decisión sobre los aspectos jurídicos de la controversia. A propósito se pueden agregar dos observaciones. La primera es que la dimensión axiológica no solo debe estar presente en la fase de "búsqueda" de la decisión, sino que adicionalmente en el discurso justificativo que el juez desarrolla en la motivación de la sentencia. Sí, como se ha dicho, elecciones de carácter valorativo caracterizan y determinan la valoración de los hechos en la aplicación de las normas, parece evidente que este aspecto esencial de la decisión no pueda permanecer implícito o secreto en el momento en el cual la decisión es expresada y justificada. En otros términos la obligación de la motivación que vincula al juez a justificar todas las elecciones que han influido sobre la decisión, implica que él exprese también los juicios de valor de los cuales depende la decisión, puesto que, solo en este modo, pueden aparecer efectivamente justificadas. De otra parte, y esta es la segunda observación, los juicios de valor no son simples opciones subjetivas, emotivas e irracionales del sujeto que las comete, por el contrario son elecciones que pueden y deben ser cumplidas según criterios racionales: estos criterios deben guiar al juez en el momento en el cual desarrolla su discurso en la decisión final de la controversia. Lo anterior implica que él haga expresa referencia a los criterios de valoración que ha adoptado, justifique eventualmente explicando la falta de adopción de criterios alternativos, y muestre como los juicios por él formulados son racionalmente justificados por la aplicación de estos criterios.

\section{La dimensión del sentido común}

Como se ha señalado previamente, la argumentación del juez tiene una necesaria estructura lógico-justificativa, sin embargo, no es un discurso formalizado: es un discurso que el juez desarrolla sirviéndose del lenguaje ordinario, y que del lenguaje ordinario presenta todas las características (fuera de los tecnicismos jurídicos, a veces útiles pero con frecuencia superfluos, de los cuales, a menudo los jueces se sirven). No valdría entonces la pena ocuparse en modo específico si no fuera porque a través del lenguaje emergen elementos de la argumentación 
que tienen una relevancia particular en el ámbito de la decisión judicial. Estos elementos se derivan del hecho que en gran medida el razonamiento del juez, y entonces, aquello que él argumenta en la motivación de la sentencia, se fundamenta sobre la referencia a nociones que, en sentido lato, pueden definirse como pertenecientes al sentido común (Taruffo, Senso comune, esperienza e scienza nel ragionamento del giudice, 2002).

Por ejemplo, el art. 115 inciso segundo cod.proc.civ. habla de "Noción de hecho que pertenece a la experiencia común" para decir que el juez puede tomarlas como fundamento de la decisión, sin que deban ser privadas en juicio, y entonces trayéndolas del conocimiento que el mismo juez posee en cuanto es sujeto que comparte una "experiencia común”. A propósito, la doctrina procesalista habla de "Hechos Notorios" y de "Máximas de la experiencia", en una tentativa por especificar de cuales nociones se trata, y de explicar por qué estas no necesitan ser probadas, dado que el juez puede traerlas de su "Ciencia Privada" (Carratta \& Taruffo, 2011: 496-501). A parte de estas especificaciones, permanece el hecho que el juez se sirve, prácticamente a cada paso, de su razonamiento, de eso que puede traer desde la cultura extrajurídica que posee como "hombre medio", y que caracteriza el contexto social y el momento histórico en el cual él formula y enuncia su decisión, Se trata, de manera más general, del stock of knowledge del cual habla William Twining, señalándolo como fuente y repertorio de las nociones no jurídicas que el juez (Pero especificando que se trata de una "complex soup of more or less well-grounded information, sophisticated models, anecdotal memories, impressions, stories, myths, proverbs, wishes, stereotypes, speculations and prejudices") (Twining, 2006: 338). O aquello de la Enciclopedia Media de la cual habla Umberto Eco (Eco, 2007: 77).

Una observación más bien obvia al respecto, es que el juez no puede dejar de servirse de nociones extrajurídicas, bien cuando formula la decisión sobre los hechos de la causa, o bien cuando interpreta las normas: por así decirlo, el sentido común es omnipresente en el razonamiento del juez, y entonces en el discurso que él desarrolla para expresar y justificar su decisión. No se puede dejar de observar aún, siguiendo las indicaciones de Twining antes citada, que el sentido común y la cultura media no son en absoluto un repertorio de nociones vinculantes, controladas, y entonces a priori idóneas para suministrar una base cognoscitiva a aquel razonamiento. A veces esto sucede en la medida que eso que los juristas llaman "hechos notorios" sea verdad para la generalidad de los afiliados, o es fácilmente controlables a través de los instrumentos normales 
del conocimiento (Taruffo en Carratta \& Taruffo, 2011: 297). Y no rara vez, "Las máximas de la experiencia" expresan la vulgarización de leyes naturales o de cualquier manera corresponden a generalizaciones dotadas de cualquier fundamento cognoscitivo (Taruffo en Carratta \& Taruffo, 2011: 504). ${ }^{14}$ En estos casos, el recurrir a la cultura media puede atribuir confiabilidad al discurso del juez y, entonces puede ser un factor importante de justificación de eso que él dice en su argumentación.

El problema nace, entonces, del hecho que muchos de los ingredientes de la soup, de la cual habla Twining, están completamente privados de fundamentos cognoscitivos y, al contrario operan en el sentido de condicionar negativamente y de distorsionar el racionamiento que se funda sobre ellos. Como ocurre para las generalizaciones spurie (engañosas), de las cuales habla Schauer (2003: 16), muchas máximas de la experiencia están completamente desprovistas de cualquier justificación y expresan prejuicios o proverbios en lugar de conocimientos (Taruffo en Carratta \& Taruffo, 2011: 509). Si es verdad, como dice Oscar Wilde, que "experiencia" es el nombre que damos a nuestros propios errores, es igualmente cierto que la (c.d) sabiduría popular este repleta de mitos y de prejuicios de la más variada naturaleza, más que de informaciones confiables alrededor de cómo son las cosas en el mundo. De otra parte, la enciclopedia media incluye también todas estas cosas, junto a nociones dotadas de cualquier grado de credibilidad y de confiabilidad.

La dimensión del sentido común es entonces omnipresente e inevitable, pero es también muy peligrosa bajo el perfil del fundamento de aquello que el juez dice (y de cómo razona), siendo muy elevado, y con frecuencia difícilmente determinable, el riesgo que del sentido común se dibuja todo menos que nociones o reglas confiables. Este riesgo aparece luego aumentado por el hecho que el recurrir al sentido común permite construir argumentos que aparecen como familiares a los destinatarios, en cuanto tienden a presentar eventos y vivencias que corresponde a eso que se cree es la "normalidad" de eventos y vivencias que aquel tipo, es decir, de construir "buenas" argumentaciones encaminadas a aparecer particularmente creíbles, y ojalá, también a ser consideradas como verdaderas (Taruffo, 2009: 67). El inconveniente y el riesgo se derivan del hecho que con frecuencia eso que parece normal y familiar, es considerado como propio porque corresponde a los estereotipos y a los prejuicios que existen en la

14 Sobre el tema de las generalizaciones válidas, ver Schauer (2003: 7). 
cultura del destinatario de la argumentación (Twining, 2006: 283, 288, 308).

Se trata, como se ve fácilmente, de un problema bastante complejo que no puede ser discutido aquí de manera adecuada. Parece todavía evidente que esto constituye un aspecto bastante delicado del razonamiento y de la argumentación que el juez pone en marcha: si la referencia al sentido común, a la experiencia y a la cultura media es inevitable, y en muchos sentidos se puede incluso decir que sea oportuna, su uso correcto requiere por parte del juez una fuerte dosis de autocrítica, en el momento en el cual él recurre a su cultura, y una fuerte disponibilidad a controlar el fundamento cognoscitivo de las nociones extrajurídicas a las cuales hace referencia.

\section{Una exclusión: La dimensión retórica}

Las varias dimensiones que se han descrito sintéticamente en las páginas que preceden se entrecruzan combinándose con varias modalidades, sea en la fase heurística de razonamiento del juez, o en el discurso que él, en la motivación de la sentencia, enuncia y justifica su decisión.

A este punto, y sin profundizar ulteriormente el argumento, vale la pena señalar que se ha excluido deliberadamente la consideración de otra hipotética dimensión que se podría definir como retórica o persuasiva. La razón de esta exclusión es que algunos aspectos retóricos pueden estar presente en la argumentación de juez, pero, contrariamente a lo que alguno podría pensar, estos aspectos no son esenciales y ni siquiera particularmente relevantes.

Por un lado, parece evidente que en la fase heurística de su razonamiento, en la cual apunta a individualizar la solución justa de la controversia, el juez no tiende a persuadir a nadie: él está buscando resolver un problema sirviéndose de métodos y criterios racionales, sin embargo, con esta actividad, la persuasión retórica no tiene nada que ver. Se podrá decir que en esta, el juez tiene en cuenta elementos (como pruebas o argumentaciones), de cuyos fundamentos o inconsistencias es "persuadido", sin embargo, esto no implica que su razonamiento tenga propiamente una dimensión retórica, teniendo en cambio, como se ha tratado de aclarar en lo precedente, una fuerte estructura lógica. Eso que determina el razonamiento del juez, en realidad no es una mera persuasión de alguna cosa, sino más bien una valoración racional de las pruebas y una justificación lógicamente fundada de la escogencia del significado de la norma que asume como regla de juicio. El juez está, por así decirlo, en la posición de "sujeto pasivo" de la persuasión, en cuanto son los abogados quienes se sirven 
de argumentos, y usan las pruebas, como instrumentos retóricos encaminados a condicionar su convencimiento (Taruffo, 2009: 43) (Twining, 2006: 24, 288) (Di Donato, 2008: 162, 173), pero esto no implica que el razonamiento del juez tenga una dimensión retórica. Al contrario, él debería evitar dejarse persuadir de la retórica de la abogacía, sirviéndose del antídoto representado por el control racional sobre su propio razonamiento.

Por otro lado, cualquier rasgo retórico puede estar presente en la argumentación con la cual el juez enuncia y justifica su decisión. Connotaciones retóricas son frecuentes en el lenguaje común, que puede ser, a criterio del estilo de quien lo emplea, más o menos enfático y sugestivo. Además, el recurrir al sentido común, del cual se ha hablado más arriba, puede tener una esencia retórica, en cuanto una argumentación que suena "familiar", puede parecer particularmente persuasiva (Twining, 2006: 283, 288, 308, 445) (Taruffo, 2009: 68). Con todo, esto no demuestra que la argumentación del juez deba necesariamente tener una esencial o relevante dimensión retórica. En realidad, el juez no debe persuadir a nadie de la bondad de su decisión: Ni las partes, ni sus abogados, ni los jueces superiores, y ni siquiera la opinión pública. Como se ha dicho varias veces, el juez tiene la obligación de justificar racionalmente su decisión aduciendo las razones por las cuales esta es considerada como verdadera y jurídicamente fundada, pero la justificación no se reduce a la persuasión retórica. Al contrario, una buena justificación puede no ser, y no tiene la necesidad de serlo, retóricamente persuasiva. Todo sumado, la demostración del teorema de Pitágoras no tiene nada de retórico, sin embargo el teorema es válido porque es lógicamente justificado. 


\section{Referencias}

Amsterdam, A., \& Bruner, J. (2000). Minding the Law. London: Cambridge.

Beltrán, F. (2007). La valoración racional de la prueba. Madrid-Barcelona-Buenos Aires: Marcial Pons.

Bruner, J. (2002). Making Stories. Law, Literature, Life. London: Cambridge.

Carlizzi, G., \& Omaggio, V. (2010). Ermeneutica e interpretazione giuridica. Torino: Giappichelli.

Carratta, A., \& Taruffo, M. (2011). ART. 112-120. Poteri del giudice. Commentario del codice di procedura civile. Bologna: Zanichelli.

Cavallone, B. (2010). In difesa della veriphobia (considerazioni amichevolmente polemiche su un libro recente di Michele Taruffo). Rivista di Diritto Processuale, 1-26.

Chiassoni, P. (2007). Tecnica dell'interpretazione giuridica. Bologna: Il Mulino.

Di Donato, F. (2008). La costruzione giudiziaria del fatto. Il ruolo della narrazione nel "processo". Milano: Codice.

Dittrich, L. (2011). La ricerca della verità nel processo civile: profili evolutivi in tema di prova testimoniale, consulenza tecnica e fatto notorio. Rivista di diritto processuale, 108-125.

Eco, U. (2007). Dall'albero al labirinto. Studi storici sul segno e l'interpretazione. Milano: Bompiani.

Eco, U. (1990). I limiti dell'interpretazione. Milano: Bompiani.

Eco, U. (1990). I limiti dell'interpretazione. Milano: Bompiani.

Guastini, R. (2004). L'interpretazione dei documenti normativi. Milano: Giuffrè.

Guastini, R. (1993). Le fonti del diritto e l'interpretazione. Milano: Giuffrè.

Luzzati, C. (1999). L'interprete e il legislatore. Saggio sulla certezza del diritto. Milano: Giuffrè.

Luzzati, C. (1990). La vaghezza delle norme. Un'analisi del linguaggio giuridico. Milano: Giuffrè.

Schauer, F. (2003). Profiles, Probabilities and Stereotypes. London: Cambridge (Mass.).

Tarello, G. (1980). L' interpretazione della legge. Milano: Giuffrè.

Taruffo, M. (2010). Contro la veriphobia. Osservazioni sparse in risposta a Bruno Cavallone. Rivista di Diritto Processuale, 995-1011.

Taruffo, M. (2002). Elementi per un'analisi del giudizio di fatto. In M. Taruffo, Sui confini. Scritti sulla giustizia civile. Bologna: Il.

Taruffo, M. (2010). Il processo civile riformato. Bologna: Zanichelli.

Taruffo, M. (1975). La motivazione della sentenza civile. Padova: Padova.

Taruffo, M. (1992). La prova dei fatti giuridici. Nozioni generali. Milano: Giuffrè. 
Taruffo, M. (2009). La semplice verità. Il giudice e la costruzione dei fatti. Bari: Laterza. Taruffo, M. (2002). Senso comune, esperienza e scienza nel ragionamento del giudice. In M. Taruffo, Sui confini. Scritti sulla giustizia civile. Bologna: Il Mulino.

Tuzet, G. (2006). La prima inferenza. L'abduzione di C.S. Peirce fra scienza e diritto. Torino: Gianppichelli.

Twining, W. (2006). Rethinking Evidence. Exploratory Essays. Cambridge: Cambridge University Press.

Viola, F., \& Zaccaria, G. (1999). Diritto e interpretazione. Lineamenti di una teoria ermeneutica del diritto. Bari: Laterza.

Wroblewski, J. (1983). Facts in Law. In J. Wroblewski, Meaning and truth in judicial decision. Helsinki: Juridica.

Zaccaria, G. (1990). L'arte dell'interpretazione. Saggi sull'ermeneutica giuridica contemporanea. Padova: Cedam. 